Çukurova Üniversitesi Mühendislik Mimarlık Fakültesi Dergisi, 34(3), ss. 171-181, Eylül 2019

Çukurova University Journal of the Faculty of Engineering and Architecture, 34(3), pp. 171-181, September 2019

\title{
TIG ve MIG Kaynağı ile İşlem Gören 304 ve 1040 Çeliklerin ITAB Bölgesindeki Mekanik Özelliklerin İncelenmesi
}

\author{
İsmail TOPCU ${ }^{* 1,2}$ \\ ${ }^{1}$ Alanya Alaaddin Keykubat Üniversitesi, Mühendislik Fakültesi, Metalurji ve Malzeme \\ Mühendisliği Bölümü, Alanya \\ ${ }^{2}$ Marmara Üniversitesi, Mühendislik Fakültesi, Metalurji ve Malzeme Mühendisliği Bölümü, \\ Istanbul
}

Geliş tarihi: 14.01 .2019

Kabul tarihi: 30.09 .2019

$\ddot{\mathbf{O} z}$

Bu çalışmada düşük ve orta karbonlu çelik türlerinin TIG ve MIG kaynağı ile kaynak bölgesinin mekanik ve mikroyapı özelliklerine kaynak parametrelerinin etkileri incelenmiştir. Kaynak uygulaması farklı akım ve tel besleme hızlarında gerçekleştirilmiş, ardından kaynaklı birleştirmelerin mekanik özelliklerini belirlemek için çekme deneyi ve sertlik ölçümleri yapılmıştır. Ayrıca mikroyapıda meydana gelen değişiklikleri belirlemek için de mikroyapı çalışmaları yapılmıştır. Bu araştırmanın amacı öncelikle kaynak tekniklerinin malzeme kaynaklanabilirliğini nasıl etkilediği ve kaynaklı çeliklerin ısıdan etkilenen bölgede (ITAB) mekanik özelliklerini ve mikroyapı karakteristiklerindeki değişimi incelemektir. Bazı metal ve kaynaklı çeliklerin mekanik özelliklerinin tayini için testler arasında karşılaştırmalar yapılmıştır. Mikroyapılar da, kaynakların performansını dinamik koşullarda etkileyebilecek herhangi bir gözenekliliğin ve diğer özelliklerin tayinine yardımcı olmak için de kullanılmıştır.

Anahtar Kelimeler: MIG/TIG, Kaynak, ITAB, 304 paslanmaz çelik

\section{Investigation of the Mechanical Properties of 304 and 1040 Steels in the HAZ Region by TIG and MIG Welding}

\begin{abstract}
In this study, the effects of welding parameters on the mechanical and microstructural properties of the weld zone and the TIG and MIG welds of low and medium carbon steels were investigated. Welding was carried out at constant welding currents and wire speeds and then tensile tests and hardness measurements were performed to determine the mechanical properties of welded joints. In addition, microstructure studies have been carried out to determine the changes in the microstructure. The aim of this research is primarily to examine how welding techniques affect material weldability and how the welded steels change in hardness, tensile test and microstructure characteristics in the heat affected zone (HAZ). Comparisons were made between the tests to determine the mechanical properties of certain metals and welded steels. Microstructures have also been used to assist in studying any porosity or other properties of the microstructure that may affect the performance of the welds under dynamic conditions.
\end{abstract}

Keywords: MIG/TIG, Welding, HAZ, 304 stainless stell

\footnotetext{
*Sorumlu yazar (Corresponding author): İsmail TOPCU, ismail.topcu@alanya.edu.tr
} 


\section{GíRiș}

Kaynak, alternatif olarak döküm, dövme, civatalı ve perçinli eklemler yerine yaygın olarak kullanılmaktadır [1]. Çeliklerde kaynak yapılması imalat sanayiinde çok muazzam bir öneme sahiptir. Ark kaynağı, ana metalin kaynaşması ve genellikle bir sarf elektrot tarafindan sağlanan metal ilavesi ile metal birleştirmek için bir elektrik arkının yoğunlaştırılmış 1sısını kullanan bir işlemdir. Kaynak yapılacak malzemeye ve kullanılan elektroda bağlı olarak ark için doğrudan veya alternatif akım kullanılabilir [2].

Ark, sürekli, metalin kaynağı ve sarf malzemesi olan elektrot teli arasındadır. Genel olarak, bir kaynak bağlantısının kalitesi, kaynak sırasında giriş parametrelerinden doğrudan etkilenir. Kaynak işlemi; bu nedenden dolayı, çok girişli ve çok çıkışlı bir ısıl işlem olarak düşünülebilir. Kaynak, kaynak metali, kaynak akımı, kaynak gerilimi, sıcaklık, elektrot, nabız frekansı, güç girişi, gaz akış hızı ve gaz bileşimi gibi kaynak metalinin nihai özelliklerini etkileyen çok çeşitli değişkenleri içerir [3].

Günümüzde üretimde kullanılan birçok kaynak yöntemi vardır. Özellikle demir ve demirdışı metallerin ve alaşımlı çeliklerin kaynakla birleştirilmesinde yaşanan sorunlar değişik kaynak yöntemlerinin geliştirilmesine sebep olmuştur. TIG/MIG kaynak yöntemleri de bu amaçla geliştirilmiş kaynak yöntemlerindendir. MIG kaynak yöntemi ile çok ince sac levhalar dâhil olmakla beraber her kalınlıkta demir esaslı ve demir dışı metal ve alaşımlarının kaynağı mümkündür [4].

Bu kaynak yöntemi diğer kaynak yöntemlerine nazaran daha iyi nüfuziyete, yüksek verimliliğe ve daha az sıçrama özelliklerine sahiptir. Bu nedenle MIG kaynak yöntemi diğer kaynak yöntemlerine göre endüstride yoğun bir şekilde kullanılmaktadır. MIG kaynağ 1 ; dolgu metalinin kaynak havuzuna otomatik olarak eklendiği ve asal bir gaz tarafindan kaynak bölgesinin korunduğu bir kaynak yöntemidir $[5,6]$. MIG kaynağı işleminde kullanılan kaynak elektrotu dolgu görevinin yanı sıra elektrik akım arkının da aynı zamanda taşıyıcısıdır. Kullanılan şarj kaynak teli çeşitli tahrik makaralarının ana işleme merkezine taşınması ile iletim noktasında akım geçişine sebep olur. $\mathrm{Bu}$ proseste kullanılan kaynak telinin uç kısmın kenarları nozul vasıtası ile koruyucu bir gaz tarafından kaplanır. Ortaya çıkan koruyucu gaz ortamdaki hava ve kimyasal empürütelerin iş parçası ile tepkimeye girmesini engeller mahiyettedir. Bu şekilde kaynak edilecek malzemenin mukavemet ve dayanımı için önlem alınmış olur. $\mathrm{Bu}$ aşamada, ortamdaki hava ve çeşitli kimyasallardan korunmak için izolasyon gazı olarak (koruyucu gaz) soy gazlar ve aktif gazlar kullanılabilmektedir. Bundan dolayı Metal Inert Gaz (MIG) kaynağı yaygın olarak tercih sebebidir. Tungsten Inert Gas welding (TIG) yöntemi üretilen elektrik arkın iş parçası ile tungsten elektrotu arasında harcanarak füzyon gücü ile ortaya çıkarttığı bir kaynak yöntemidir. $\mathrm{Bu}$ kaynak yönteminde de kullanılan elektrot, meydana gelen ark ve kaynak ortamı koruma gazı kullanılarak kaynak yapılan atmosferden ve çeşitli kimyasallardan korunurlar. İnert gaz nozul yardımı ile kaynak yapılan ortama verilir ve mevcut atmosferik havayı bertaraf eder. $\mathrm{Bu}$ kaynak yöntemi diğer ark kaynak yöntemlerinde ayrilır. Çünkü bu yöntemde diğer yöntemlerdeki gibi dolgu elektrotu kullanılmaz [7-9].

Paslanmaz çelik, korozyona karşı mükemmel direnç gösteren ve mutfak eşyaları, nakliye, inşaat yapıları ve çok daha fazlası için zorunlu olarak kullanılan Fe içerikli alaşımların bir ailesidir [10]. Paslanmaz çelikler \%8-25 oranında demir, $\% 12$ 'den fazla Nikel ve \%30'dan fazkla krom ve alaşım elementleri içerdikleri için hem korozyona hem de yüksek sıcaklıklara karşı dayanırlar. Paslanmaz çelikler ferritik, östenitik, martensitik, iki katlı ve çöktürme çelikleri olarak farklı sınıflara ayrılırlar [11]. Östenitik paslanmaz çeliklerin mükemmel mekanik özellikleri, onları nükleer santraller için önemli bir yapısal malzeme haline getirmiştir [12]. Reaktör soğutucu boruları, vana gövdeleri ve gemi iç parçaları bu çeliklerden imal edilir. Bununla birlikte, segregasyon, sekonder fazların çökelmesi, gözenekliliklerin varlığ1, katılaşma çatlaması ve isıdan etkilenen bölgede (ITAB) tane büyümesi gibi füzyon kaynak işlemleriyle ilişkili metalürjik değişikliklere bağlı 
olarak kaynak yapısının zayıf mekanik özelliklere sahip olmasına neden olmaktadır [12]. Geleneksel östenitik paslanmaz çeliğin temel bileşimi \%18 krom ve \%8 nikel ve düşük oranlarda molibden, titanyum, niyobyum, bakır ve azot bulunur. Mükemmel korozyon direnci, üstün sürünme davranışı ve düşük sıcaklıklarda darbe dayanımı gibi mühendislik özellikleri sergiler. Paslanmaz çelik imalatı için kaynak işlemi uygulanan yaygın yöntemlerdendir. Fakat ark kaynağı işlemi ile ITAB'daki tane sınırları boyunca kaba taneler ve karbür oluşumu meydana gelir. Krom açısından zengin olan daha kaba yapı ve karbürler kaynağın mekanik özelliklerini kötü etkiler [13]. Bu dezavantajı ortadan kaldırmak birleştirilecek malzemeler genellikle TİG kaynağı ile birleştirilirler. Temel olarak sarf olmayan tungsten elektrot ve iş parçası arasında bir ark üretimi oluşur. Genellikle argon olan inert bir gaz, ark, elektrot ve erimiş havuzu atmosferik kontaminasyondan korur. TIG kaynağı, paslanmaz çeliklerden demir dışı alaşımlara kadar uzanan malzemeler için kaliteli kaynaklar elde etmek amacıyla, aynı zamanda kalın malzemelerin yanı sıra, diğer malzemelerin birleştirilmesine de eşit derecede uygundur [15].

Bu çalışmada, AISI 304 paslanmaz çelik ve 1040 orta karbonlu çelik levhaların TIG/MIG kaynak işleminin ITAB'ın mikroyapısı, gerilme mukavemeti ve sertliği üzerindeki etkileri incelenmiştir. Metaller ile ısıdan etkilenen bölge arasında sertlik, gerilme ve mikroyapıları karşılaştırılıp, mikroyapıdaki gözenekler veya çatlaklar gibi kusurları gözlemlemenin yanı sıra sertlik değerlerindeki farklılıkları da değerlendirilmiştir. Sertlik ve mikroyapının nasıl değiştiğini görmek için iki farklı metal ve iki farklı kaynak (TIG ve MIG ) yöntemi incelenmiştir.

\section{MATERYAL VE METOT}

Bu çalışmada, 220x100x6 mm ebatlarında AISI 1040 ve AISI 304 çelik levhalar kaynak işlemi gerçekleştirilerek proses parametrelerinin kaynaklanabilirliğine ve mekanik özelliklere etkisi test edilmiştir. V kaynak ağzı açılarak üretilmiş olan kaynaklı numunelerde, kaynak kalitesini belirlemek amacıyla gözle muayene, mikroyap1, mikrosertlik ölçümleri ve mekanik özellik tayini testler yapılmıştır. Kullanılan AISI 1040 ve AISI 304 çeliklerin kimyasal bileşim (\% ağırlık olarak) değerleri Çizelge 1'de verilmiştir. Kaynak yapılan malzemeler açık havada soğutulduktan sonra, curufları ince zımpara ile temizlenmiştir. Birleştirme işlemlerinde; TIG kaynağında Inverter tipi, MIG kaynağında MIG RV 500 tipi kaynak makinaları kullanılmıştır. TIG kaynağı darbeli akımda gerçekleştirilmiş olup akım olarak 85A seçilmiştir. Deneyler esnasında kullanılan kaynak parametreleri Çizelge 4'de verilmiştir.

Kaynaklı parçaların başlangıç ve bitiş kısımlarından $20 \mathrm{~mm}$ metak kesme makinesi ile kesilerek atılmıştır. Kalan kısımlarından çekme deneyi, mikrosertlik deneyi ve mikroyapı incelemeleri için numuneler hazırlanmıştır. Çekme numuneleri TS EN 895 standartına göre her bir kaynaklı bağlantıdan 3'er adet hazırlanmış ve Instron 8802 mekanik test cihazında $2 \mathrm{~mm} / \mathrm{dk}$ ilerleme hızında çekilmiştir. Mikrosertlik test numuneleri (Esas metaller, kaynak metalleri ve birleştirmelerin ITAB'1) Şekil 1'de verilen ölçülerde ve standarda göre her bir numuneden 2 veya 3 'er adet hazırlanmıştır.

Mikroyapı numuneleri, bakalite alma işleminden sonra standart metalografik numune hazırlama işlemlerine (zımparalama, parlatma) tabi tutulmuştur. Hazırlanan numunelerin mikroyapı çalışmaları optik mikroskop ile gerçekleştirilmiştir. Hazırlanan mikroyapı numuneleri aynı zamanda mikrosertlik ölçümü için de kullanılmıştır. Mikrosertlik ölçümleri, Futuretech 7000 marka cihaz ile 500 g yük uygulanarak sonuçlar her bir bölgede gerçekleştirilen 5 ölçüm sonucunun ortalaması alınarak değerlendirilmiştir.

Instron 8802 servohidrolik çekme test cihazında çekme deneyleri yapılmıştır. Birinci grup \%0,08 oranına sahip düşük karbonlu (304) paslanmaz, ikinci grup ise $\% 0,4$ oranına sahip orta karbonlu çeliklerdir. Üçer adet iki farklı numune grubuna TIG ve MIG gibi iki farklı tipte kaynak yöntemi uyguland. Uygulanan kaynak tiplerinin şematik olarak gösterimi Şekil 1'de görülmektedir. 

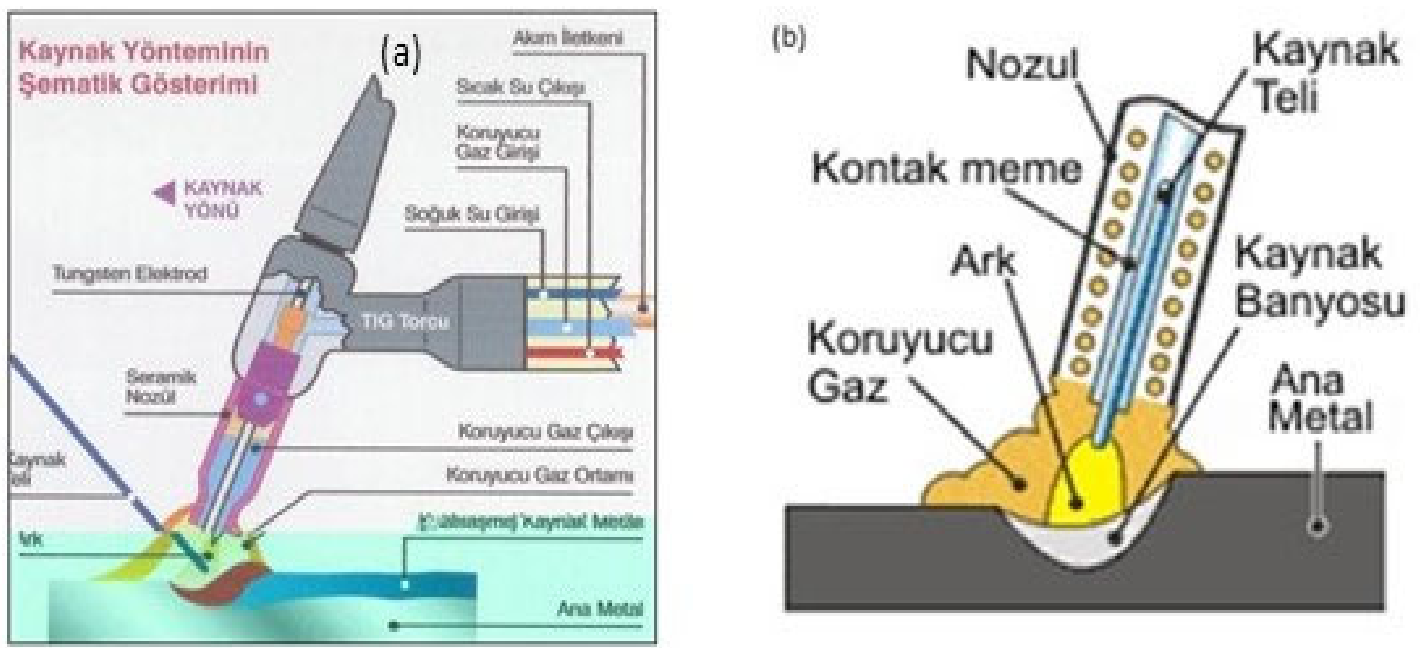

Şekil 1. TİG ve MİG kaynak yöntemlerinin şematik gösterimi (a)TIG kaynak yöntemi (b) MIG kaynak yöntemi

$\mathrm{Bu}$ çalışma kaynak tekniğinin dezavantajlarını azaltarak endüstri için daha iyi ve kullanışlı yöntemler sağlamayı amaçlamaktadır. Aşağıda Çizelge 1'de anılan farklı kaynak yöntemleri ile birleştirilecek olan malzemelerin spektral analizleri görülmektedir.
Çalışılacak kaynak işlemlemlerinde kullanılacak iki farklı malzemenin mekanik özellikleri Çizelge 2'de verilmiştir.

Kaynak işleminde kullanılan özellikli birleştirme elektrodlarına ait kimyasal bileşimi Çizelge 3'te verilmiştir.

Çizelge 1. Kaynak edilecek metallerin kimyasal bileşimleri

\begin{tabular}{|l|c|c|c|c|c|c|c|}
\hline \multicolumn{7}{|c|}{ Kimyasal Bileşim (\%) } \\
\hline Malzemeler & $\mathrm{C}$ & $\mathrm{Mn}$ & $\mathrm{P}$ & $\mathrm{S}$ & $\mathrm{Si}$ & $\mathrm{Cr}$ & $\mathrm{Ni}$ \\
\hline AISI 1040 & 0,44 & 0,74 & 0,032 & 0,041 & 0,30 & - & - \\
\hline AISI 304 & 0,07 & 1,92 & 0,041 & 0,024 & 0,71 & 19,1 & 9,2 \\
\hline
\end{tabular}

Çizelge 2. Kaynak edilecek metallerin mekanik özellikleri

\begin{tabular}{|l|c|c|c|c|}
\hline \multicolumn{5}{|c|}{ Mekanik Özellikleri } \\
\hline Malzemeler & $\begin{array}{c}\text { Çekme Mukavemeti } \\
\text { MPa }\end{array}$ & $\begin{array}{c}\text { Akma Mukavemeti } \\
\text { MPa }\end{array}$ & Sertlik Değeri (HV) & \%Uzama \\
\hline AISI 1040 & 580 & 320 & 226 & 16 \\
\hline AISI 304 & 515 & 205 & 210 & 40 \\
\hline
\end{tabular}

Çizelge 3. Ek (Elektrod) kaynak metallerin kimyasal bileşimleri

\begin{tabular}{|l|c|c|c|c|c|c|c|c|}
\hline \multicolumn{1}{|c|}{ Kimyasal Bileşim (\%) } \\
\hline Elektrodlar & $\mathrm{C}$ & $\mathrm{Mn}$ & $\mathrm{P}$ & $\mathrm{S}$ & $\mathrm{Si}$ & $\mathrm{Cr}$ & $\mathrm{Ni}$ & $\mathrm{Mo}$ \\
\hline ER308L (TIG) & 0,021 & 1,50 & 0,03 & 0,04 & 0,40 & 18,5 & 11,5 & 2,44 \\
\hline ER308L Si (MIG) & 0,030 & 1,75 & 0,03 & 0,03 & 0,85 & 19,5 & 10 & - \\
\hline
\end{tabular}


Birleştirme işlemi için kaynak parametreleri Çizelge 4'te verilmiştir.

Çizelge 4. Kaynak işlemlerinde kullanılan kaynak parametreleri

\begin{tabular}{|l|c|c|c|c|c|c|}
\hline $\begin{array}{c}\text { Kaynak } \\
\text { Yöntemi }\end{array}$ & $\begin{array}{c}\text { Kaynak } \\
\text { akımı (A) }\end{array}$ & $\begin{array}{c}\text { Kaynak Hızı } \\
(\mathbf{c m} / \mathbf{d a k})\end{array}$ & $\begin{array}{c}\text { Isı Girdisi } \\
(\mathbf{k j} / \mathbf{m m})\end{array}$ & $\begin{array}{c}\text { Kullanılan } \\
\text { Gaz }\end{array}$ & $\begin{array}{c}\text { Ek metak } \\
\text { Çapı (mm) }\end{array}$ & Akım türü \\
\hline TIG & 85 & 9,5 & 1,2 & \%99 Argon & 2,4 & $\mathrm{DC}(-)$ \\
\hline MIG & 85 & 9,5 & 0,72 & Argon ve $\mathrm{CO}^{2}$ & 0,8 & $\mathrm{DC}(+)$ \\
\hline
\end{tabular}

Hem AISI 1040 çeliği hemde AISI 304 paslanmaz çelik levhaların metal inert gaz, tungsten inert gaz (MIG/TIG) kaynakları ile sırasıyla alın kaynakları yapıldı. Kaynaklanan iki farklı çelik malzemenin TIG ve MIG kaynaklı eklemin malzeme karakterizasyonu ile ilgili çalışmalar sunulmaktadır. Kaynak işlemleri sonrası sırasıyla MIG ve TIG kaynak işlemlerinin mekanik özellikleri incelenmiş ve metalografik incelemeleri yapılmıştır.

Paslanmaz çelik elektrotlar kaynağında kullanılacak olan esas metal bileşiminin seçiminde, çevrenin özellikleri, sıcaklık ve mekanik stres ortamı göz önünde bulundurulmuştur. Paslanmaz

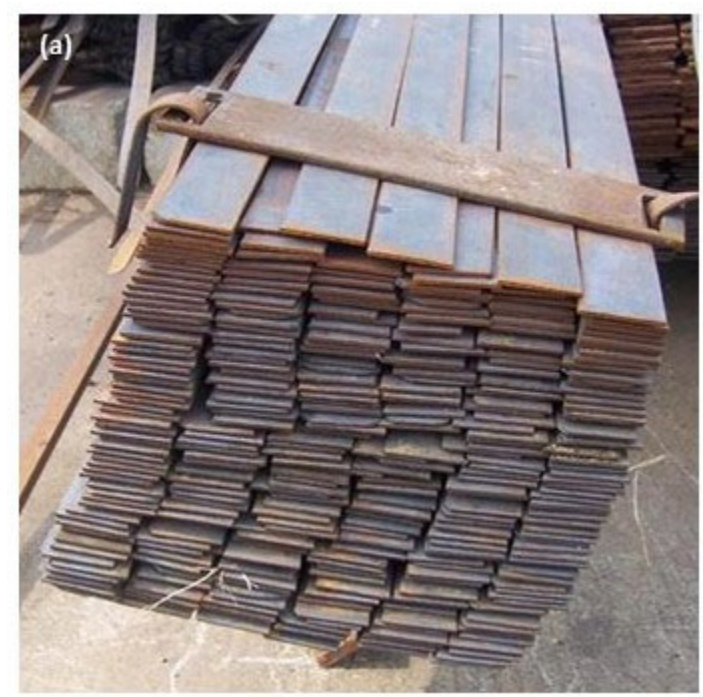

tip elektrotlar $250-300^{\circ}$ de 2 saat kurutuldu. Paslanmaz çelikler için farklı bileşim ve farklı yapılarda olan farklı elektrot tipleri bulunmaktadır. Örneğin, 308L, 308Mo, 316L, 309L, 310, 312, 316i, 347, 410, 318, 308, 318M-R gibi birçok elektrod tipi bulunmaktadır. Çalışmada bu elektrod tipleri içinden amaca uygun olarak 308L paslanmaz çelik kaynak elektrod serisi kullanıldı. Öncelikle, 304 ve 1040 çelik sac metal kesme makinesi ile $100 \mathrm{mmx} 100 \mathrm{mmx} 4 \mathrm{~mm}$ 'ye kadar kesim yapıldı. 1040 çelik sert malzemedir ve $4 \mathrm{~mm}$ kalınlıkta bulunması oldukça zordur dolayısı ile bulunan levhalar vargel de soğutucu siv1 kullanılarak ısıdan etkilenmeyecek şekilde $4 \mathrm{~mm}$ ye indirgenmiştir.

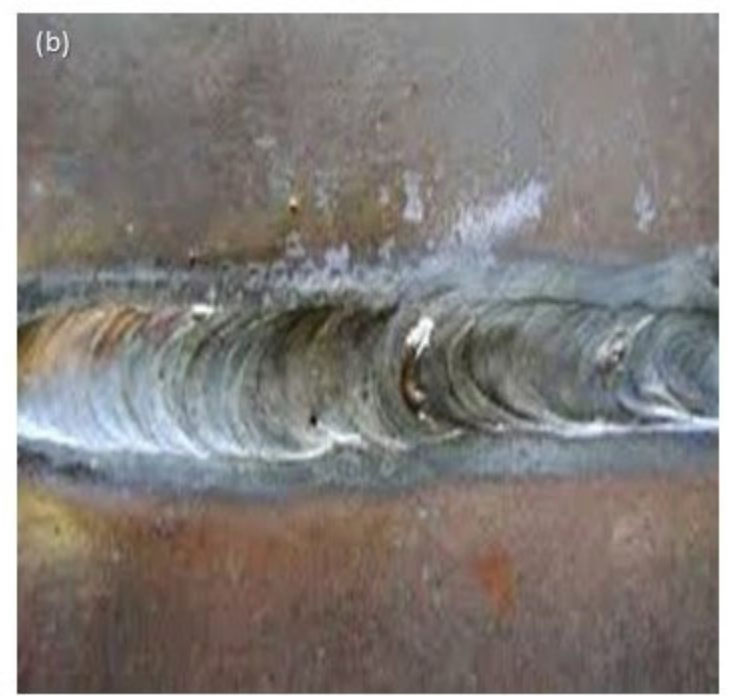

Şekil 2. (a)Kaynak öncesi 1040 orta karbonlu çelikler (b) Kaynak sonrası 1040 orta karbonlu çelik numune

TIG/MIG kaynak uygulamaları için yapılacak olan çekme test numuneleri ilgili ulusal ve uluslararası standarlar göz önüne alınarak (ISO 6892-1(2016) ve ASTM E8/8M (2016)) ikişer adet test numunesi 
üretilmiştir. Üretilen test numunelerinin boyutsal detayları Şekil 3'te verilmiştir. Testler Instron 8802 servohidrolik test cihazında $23{ }^{\circ} \mathrm{C}$ oda sicaklığında ve uygun nem koşullarında (ISO 6892-1(2016) ve ASTM E8/8M (2016)) standartlarına göre test edilmiştir.

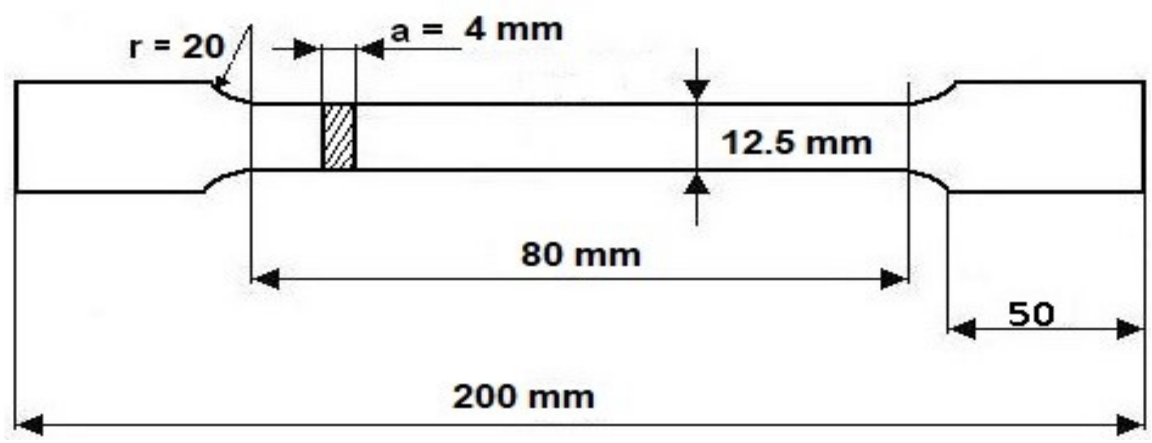

Şekil 3. TSE 138 e göre standart çekme test numunesi teknik resmi

İlgili TSE ve ASTM standardına göre üretilmiş olan çekme çubukları Şekil 4'te görülmektedir.
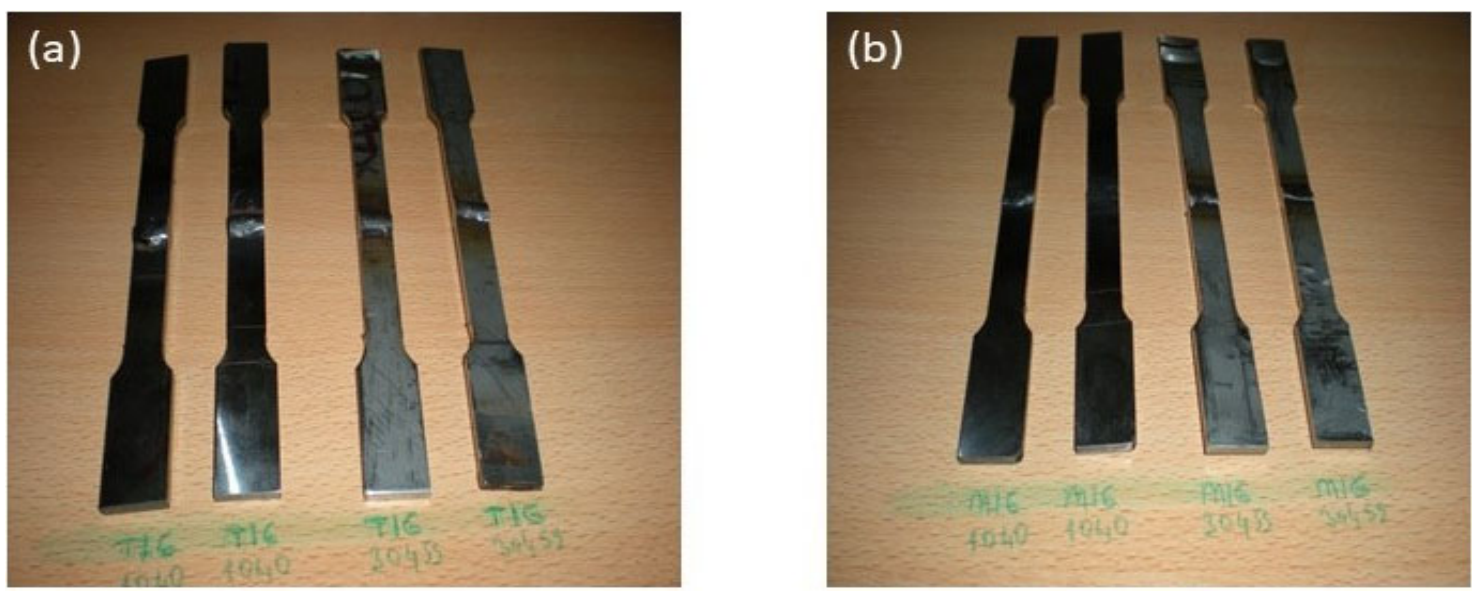

Şekil 4. 304/1040 malzemelerinin TIG ve MIG kaynağı yapılmış çekme test numuneleri

Her uygulama için ikişer adet test numunesi üretilmiştir. Elde edilmiş olan sonuçlar iki adet çekme testi sonucunun aritmetik ortalamasıdır. İki farklı malzeme ve iki farklı kaynak yöntemi ile üretilmiş olan kaynak parçasından kesilerek sırası ile numaralandırılmıştır. Numaralandırılmış olan kaynak numuneleri sıcak kalıplama ile bakalite alınarak metalografik incelemeler ve sertlik testleri için numuneler hazırlanmıştır. Bakalite alınarak hazırlanan bütün numuneler sırasıyla 400, 600, 800 ve 1000 tane boyutlu $\mathrm{SiC}$ zimpara ile özenle zimparalandıktan sonra $\mathrm{Al}_{2} \mathrm{O}_{3}$ pasta kullanılarak çuha ile parlatılmıştır. Bakalite alınarak parlatılmış olan bu numuneler sertlik ölçüm testleri için Future Tech. FM-7000 mikro sertlik ölçüm cihazında test edilmiştir. Kaynaklı numunelerin Mikro sertliği Vickers $136^{\circ}$ 'lik elmas uç ile 500 gr ağırlık kullanılarak HV (0.5) Vickers yöntemi ile yapılmıştır. Her örnek için test yükü $500 \mathrm{~g}$ ve bekleme süresi 15 saniyedir. Sertlik ölçme testinde her numune üzerinde yaklaşık olarak beş adet ardışık ölçüm yapılmış olup nihai olarak elde edilmiş olan beş değerin 
aritmetik ortalaması sertlik değeri olarak kabul edilmiştir. Hazırlanmış olan mikrosertlik test numuneleri Şekil 5 'te gösterilmiştir.
ITAB bölgesinden başlanarak belirli aralıklarla ölçümü yapılan sertlik numunesi ve izleri Şekil 6 da gösterilmiştir.
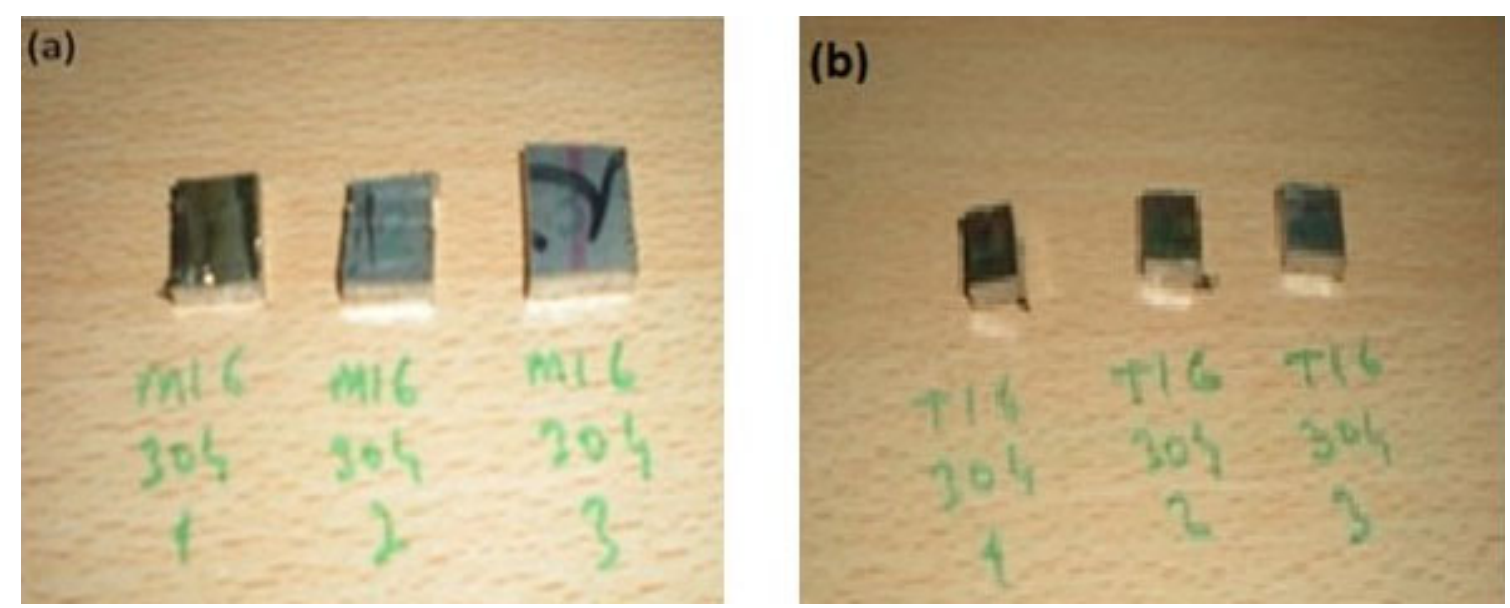

Şekil 5. ITAB bölgesi (1-2-3) TIG kaynaklı 304/1040 malzemeleri sertlik testi numuneleri
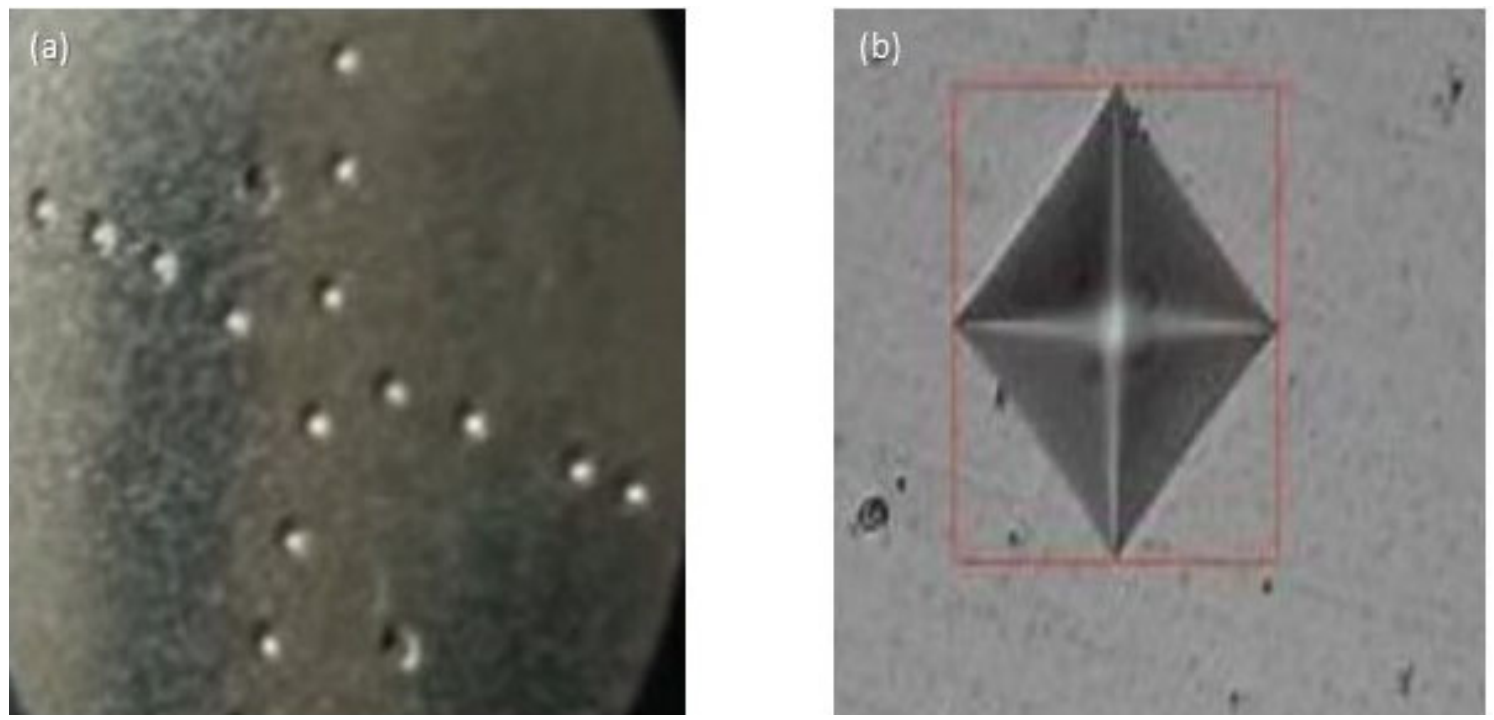

Şekil 6. ITAB bölgesi (1-2-3) MIG kaynaklı 304/1040 malzemesi sertlik testi numuneleri

Metalografik muayene için kullanılan numunelerin her biri TIG/MIG kaynağı ile kaynak paramatrelerine titizlikle bağlı kalınarak üretilmiş olan numunelerdir. Optik incelemeler gerçekleştirmek içinde aynı yöntemlerle hazırlanmış numunelerin dağlanması için kroll reaktifi $(3 \mathrm{~mL} \mathrm{HF}, 100 \mathrm{~mL} \mathrm{H} 2 \mathrm{O}$ içinde $6 \mathrm{~mL}$ $\mathrm{HNO}_{3}$ ) kullanıld1 [13]. İncelenen numuneler kaynak bölgesinden kesilerek ITAB ve çevre kesitlerinden metalografik numuneler hazırlanmıştır. Tüm numuneler, 240, 500, 800 ve 1000 tane yapılı SiC zımpara kâğıtları ile hafifçe zımparalanıp ardından kroll solüsyonları ile dağlanmıştır. Parçaların mikroyapıları optik mikroskopu ile incelendi. Numune hazırlama işlemi sonrası (X200) hazırlanmış olan numuneye 
metalografik olarak düşey kesitlerden bakıldı. incelendiğinde yapıda ince dendiritik yapıların Şekil 7'de görüleceği üzere mikroyapı oluştuğu net olarak görülmektedir.

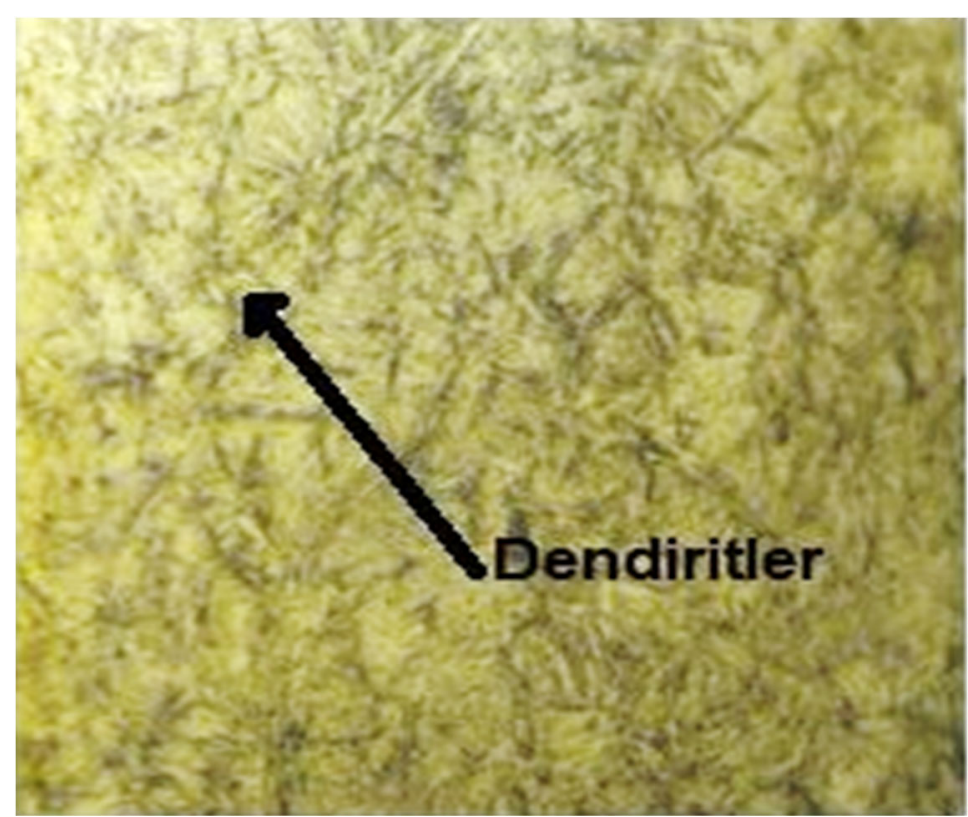

Şekil 7. MIG kaynaklı birleştirilen 304 numunenin mikroyapı görümtüsü

\section{DENEYSEL ÇALIŞMALAR VE BULGULAR}

Ülkemizde sık rastlanmayan fakat sanayimizde uygulanmaya başlandıktan sonra çok yaygınlaşan TIG ve MIG kaynakları ile ilgili çok yönlü çalı̧̧alar yapılmıştır. Fakat yapılan bu çalışmada sanayiye dönük düşük karbonlu çelikler ve paslanmaz çelik kaynaklarlı malzemelerin mekanik özellikleri yapılan literetür taramalarında fazlaca deneysel olarak bir arada yapılmadığı kanısına varılmıştır. Düşük karbonlu çelik (1040) ve paslanmaz çeliklerin (304) farklı kaynak yöntemleri kullanılarak üretilmiş olan kaynaklı numunelerin mikosertlik testleri yapılmıştır. MIG/TIG kaynağı yapılmış malzemelerin ITAB bölgesinden kaynak bitimine doğru olan bölgelerden edilen sertlik test sonuçları Çizelge 5 ve Çizelge 6'da gösterilmiştir.

Çizelge 5. MIG kaynaklı malzemelerin sertlik ölçümleri

\begin{tabular}{|c|c|c|}
\hline 1040 Orta Karbonlu Çelik & 304 paslanmaz Çelik & ITAB \\
\hline $358 \mathrm{HV}$ & $392 \mathrm{HV}$ & 1 \\
\hline $312 \mathrm{HV}$ & $351 \mathrm{HV}$ & 2 \\
\hline $275 \mathrm{HV}$ & $304 \mathrm{HV}$ & 3 \\
\hline
\end{tabular}

Çizelge 6. TIG kaynaklı malzemelerin sertlik ölçümleri

\begin{tabular}{|c|c|c|}
\hline 1040 Orta Karbonlu Çelik & 304 paslanmaz Çelik & ITAB \\
\hline $332 \mathrm{HV}$ & $372 \mathrm{HV}$ & 2 \\
\hline $192 \mathrm{HV}$ & $341 \mathrm{HV}$ & 3 \\
\hline $186 \mathrm{HV}$ & $291 \mathrm{HV}$ & \\
\hline
\end{tabular}


Ark, sürekli olarak kaynak metali ve sarf malzemesi olan elektrot teli arasındadır. Genel olarak, bir kaynak bağlantısının kalitesi, kaynak sırasında giriş parametrelerinden doğrudan etkilenir. Kaynak prosesleri birçok paramatreye sahip karmaşık uygulamalardır. Bu nedenle kabul edilebilir standartlara ihtiyaç duyulmaktadır.

Yapılmış olan kaynak işlemi sonucunda mikro yapıda geçiş ve ısıdan etkilenen bölgelere doğru taneler arası ostenit oluşturuldu. Meydana gelen bu mikroyapısal faz değişimi kaynaklı TIG, MIG kaynağının en yüksek sertlik değerleri $392 \mathrm{HV}$ ve 372 HV olarak bulunmuştur. Mikro sertlik ölçümleri değerleri ITAB bölgesi ve dişında farklılık gösterdi. ITAB bölgesinde düşük bu bölge dışında ise daha hızılı soğutulması sonucunda da daha yüksektir. Mikro sertlik değerleri sırası ile ITAB bölgesi sağ ve soluna merkezden uzaklaşarak sırasıyla azalmıştır. Mikroyapı değişimi de söz konusu farklı 1sı değişimlerinden dolayı ITAB bölgesi merkezli olarak belirtilen numunelerde daha büyük dendritler meydana gelmiştir. Kaynaklı yapıların mikro sertlik değerleri ITAB bölgesinden uzaklaştıkça azalmıştır. Ayrıca kaynaklı örneklerin sertlik değerleri ana metallerden daha yüksek olduğunu görülmüştür.

Kaynak sırasında ısının mikroyapının yeniden kristalleşmesini hızlandırdığını, bunun da deformasyon derecesine bağlı olduğunu göstermektedir. Artan deformasyon miktarı sonucunda mukavemetin ve sertlik değerlerinin artırmaktadır ve bu bilnen genel bir doğrudur.

İki farklı kaynak yöntemi kullanılarak oluşturulan kaynaklı birleştirmelerden elde edilen çekme numunelerine yapılan çekme testleri sonuçları Çizelge 7'de görülmektedir. Numunelerin tümünde kopma işlemi kaynaklı bağlatı esas metal tarafında ve kaynak ergime sınırına bitişik olan ITAB'ın iri taneli bölgesinde meydana gelmiştir.

Çizelge 7. Çekme testi sonuçları

\begin{tabular}{|l|c|c|c|c|}
\hline & MIG304 & MIG1040 & TIG304 & TIG1040 \\
\hline Çekme Dayanımı MPa & 678 & 651 & 662 & 631 \\
\hline Akma Dayanımı MPa & 397 & 382 & 377 & 367 \\
\hline E Modül MPa & 5142 & 4340 & 5579 & 4020 \\
\hline \%Uzama & 53,99 & 25,0 & 46,64 & 12,5 \\
\hline
\end{tabular}

Çizelge 7 incelendiğinde iki değişik kaynak yöntemiyle birleştirilmiş bağlantılardan en yüksek çekme dayanımı $\left(678 \mathrm{~N} / \mathrm{mm}^{2}\right)$ MIG kaynağı ile birleştirmiş 304 paslanmaz çeliklerde elde edilmiştir. Çok büyük bir fark olmamakla beraber TIG kaynağı ile birleştirilmiş 304 paslanmaz çeliklerde ölçülen çekme dayanımı da $662 \mathrm{~N} / \mathrm{mm}^{2}$ olarak bulunmuştur. MIG/TIG kaynakları ile birleştirilen 304 paslanmaz çelik çekme dayanımlarının 1040 orta karbonlu çeliğin çekme dayanımından daha yüksek olduğu belirlenmiştir.

Çekme deneyi sonucunda elde edilen \%uzama değerleri incelendiğinde, TIG kaynaklı bağlantı ortalama \%15 (1040) ve \%46,64 (304) MIG kaynaklı bağlantı ortalama \%25 (1040) ve \%59,99 (304) uzama değeri elde edilmiştir. Kaynaklı bağlantıların \%uzama değerlerinin birbirlerine çok yakın olduğu görülmektedir ve iki farklı kaynak yöntemiyle birleştirilen iki farklı materyel bağlantılarından 1040 çeliğini TIG kaynağındaki ortalama \%uzama değerlerinin her iki esas malzemeden daha düşük olduğu görülmüştür. Kaynaklı bağlantılardaki \%uzama miktarının azalmasının nedeni, kaynak esnasında sertliği artarak deforme olmayan bölgelerin varlığına bağlanabilir[16].

\section{SONUÇ}

Bu çalışmada, 304 ve AISI 1040 orta karbonlu çeliklerin kaynaklanabilme özelliklerini incelenmiştir. İki farklı çeliğin mikroyapıları, mikrosertlik ve çekme testi özelliklerini inceleyerek söz konusu malzemelerin mekanik davarnışları hakkında bilgi edinmektir. Isıdan 
etkilenen bölge, kaynaklı çeliğin performansını nasıl etkileyecği konusuna açıklık getirmektir;

i) Yapılan TIG ve MIG kaynak yöntemleri sonucunda birleştirilmiş numunelerdin çekme testleri sonucunda, en yüksek çekme dayanımı (678 MPa/662 $\mathrm{MPa})$ TIG/MIG kaynağ1 ile birleştirmiş 304 paslanmaz numunelerden elde edilmiştir.

ii) Kaynaklı numunlerin hepsinde kopma işlemi kaynaklı bölgenin ve ITAB'ın dışındaki iri taneli bölgede meydana gelmiştir. Kopmanın ITAB bölgesi dışında oluşması bu da çalışmanın doğruluğunu teyit etmektedir. Ayrıca 1040 orta karbonlu çeliğin düşük kaynak kabiliyeti sergilediği kolayca görülebilir.

iii) Yapılan mikrosertlik ölçümlerinde, en yüksek sertlik değerini TIG AISI 304 kaynaklı birleştirmelerin ITAB bölgelerinden (392 HV) ölçülmüştür.

iv) Optik mikroskop çalışması sonucunda, ergiyip katılaşmış kaynak metalinin eş eksenli dendritik tanelerden meydana geldiği belirlenmiştir.

v) Mikroyapı ile mekanik özelikler biribiri ile uyumlu bir seyir izlemektedir. Bu etkilerin anlaşılması, çeliklerin performansının optimize edilmesi için kritik öneme sahiptir. Şüphesiz, kaynak endüstrisi yükselecek ve mekanik özelliklerini geliştirecek malzemelerin incelenmesini sağlayacak şekilde gerçekleşeceği öngörülemektedir.

vii) Yapılan bütün incelemer sonucunda MIG kaynak yöntemi ile yapılan bütün birleştirmeler TIG kaynak yöntemine göre daha iyi mekanik sonuçlar sonuçlar vermiştir. Bundan dolayı MIG (Metal Inert Gas) genelde otomatik kaynak yöntemi ile toprak altı ana çelik boru hatlarında istenen mekanik özelliklere cevap verdiği için hem daha işlevsel hemde seri yönteme uygun olduğu için tercih edilir. TIG (Tungsten Inert Gas) kaynak yöntemi de NDT gerektiren kullanılan boru çap 4"'e kadar olan kök-dolgu kaynakları gibi uygulamalar da kullanılır.

\section{KAYNAKLAR}

1. Bilici, M.K., Bakir, B., Bozkurt, Y., Çalış, Ç., 2016. Taguchi Analysis of Dissimilar Aluminum Sheets Joined by Friction Stir Spot Welding, DOI: 10.5505/pajes.2015.06641.

2. Çalıülü, U., Dikbaş, H., Taşkın, M., 2012. Microstructural Characteristic of Dissimilar Welded Components (AISI 430 Ferritic-AISI 304 Austenitic Stainless Steels) by $\mathrm{CO}_{2}$ Laser Beam Welding (LBW) Gazi University Journal of Science, 25(1), 35-51.

3. Taskin, M., Ozan, S., Kolukisa, S., 2006. The Effect of the Process Temperature on the Bondability in Diffusion Bonding of AISI 430 with Nodular Cast Iron, Practical Metallography, 43(6), 293-305.

4. Ozan, S., Taskin, M., Kolukisa, S., 2006. The Effect of the Process Temperature on the Bondability in Transient Liquid Phase (TLP) Diffusion Bonding of AISI 430 Ferritic Stainless Steel with Nodular (Spheroid) Cast Iron Using A Copper Interlayer, Practical Metallography, 43(11), 575- 585.

5. Tabish, T.A., Abbas, T., Farhan, M., Atiq, S., Butt, T.Z., 2014. Effect of Heat Input on Microstructure and Mechanical Properties of the TIG Welded Joints of AISI 304 Stainless Steel International Journal of Scientific \& Engineering Research, 5(7), 1532.

6. Tanaka, M., Shimizu, T., Terasaki, T., Ushio, M., Koshiishi, F., Yang, C.L., 2006. Effects of Activating Flux on Arc Phenomena in Gas Tungsten Arc Welding, Science and Technology of Welding \& Joining, 5 (6), 397-402.

7. Tseng, K.H., Hsu, C.Y., 2014. Performance of Activated TIG Process in IJSER International Journal of Scientific \& Engineering Research, 5(7), 1541.

8. Kurt, H.İ., Samur, R., 2013. Study on Microstructure, Tensile Test and Hardness 304 Stainless Steel Jointed by TIG Welding, International Journal of Science and Technology, 2:163-168.

9. Yan, J., Gao, M., Zeng, X., 2010. Study on Microstructure and Mechanical Properties of 304 Stainless Steel Joints by TIG, Laser and 
Laser-TIG Hybrid Welding Optics and Lasers in Engineering, 48, 512-517.

10. Sakthivel, T., Vasudevan, M., Laha, K., Parameswaran, P., Chandravathi, K.S., Mathew, M., Bhaduri, A.K., 2011. Comparison of Creep Rupture Behaviour of Type 316L(N) Austenitic Stainless Steel Joints Welded by TIG and Activated TIG Welding Processes, Materials Science and Engineering A, 528, 6971-6980.

11. Sathiya, P., Aravindan, S., Haq, A.N., 2007. Effect of Friction Welding Parameters on Mechanical and Metallurgical Properties of Ferritic Stainless Steel, the International Journal of Advanced Manufacturing Technology, 31(11-12), 1076-1082.

12. Fujii, H., Sato, T., Lua, S., Nogi, K., 2008. Development of an Advanced A-TIG (AA-TIG) Welding Method by Control of Marangoni Convection, Materials Science and Engineering A, 495, 296-303.

13. Topcu, I., Gulsoy, H.Ö., Kadioglu, N., Gulluoglu, A.N., 2009. Processing and Mechanical Properties of B4C Reinforced Al Matrix Composites-Journal of Alloys and Compounds, 482(1-2), 516-521.

14. Kaya, Y., 2010. AISI 304 ve AISI 430 Paslanmaz Çeliklerin TIG, MIG ve Örtülü Elektrod Ark Kaynağıyla Birleştirlebilirliğinin Araştırılması, Gazi Üniversitesi Mühendislik ve Mimarlık Fakültesi Dergisi, 25(3), 549-557.

15. Gençalp İrizalp, S., Saklakoğlu, N., İldaş, G., Demirok, S., 2018. 1.2714 Çeliği Üzerine Sert Dolgu Kaynağı ile Kaplanmış Fe-Cr-V Esaslı Alaşımın Malzeme Özelliklerinin İncelenmesi. Çukurova Üniversitesi Mühendislik-Mimarlık Fakültesi Dergisi, 33(1), 35-46. DOI: 10.21605/cukurovaummfd. 420400

16. Topcu, İ., Güllüoğlu, A.N., Bilici, M.K., Gülsoy, H.Ö., 2018. Investigation of Wear Behavior ofTi-6Al-4V/CNT Composites Reinforced with Carbon Nanotubes, Journal of the Facultyof Engineering and Architecture of Gazi University (2018), https://doi.or./10. 17341/gazimmfd.460542. 
